\title{
\& Research Square \\ Robust asymmetry of the future Arctic polar vortex is driven by tropical Pacific warming
}

Shinji Matsumura ( $\nabla$ matsusnj@ees.hokudai.ac.jp )

Hokkaido University https://orcid.org/0000-0001-6824-2573

Koji Yamazaki

Hokkaido Universy https://orcid.org/0000-0002-3189-3839

Takeshi Horinouchi

Hokkaido University https://orcid.org/0000-0002-2296-1975

\section{Article}

Keywords: Circumpolar Westerly Jet, Radiative Cooling, Teleconnection, Vertical Wave Propagation

Posted Date: November 30th, 2020

DOl: https://doi.org/10.21203/rs.3.rs-99810/v1

License: (1) This work is licensed under a Creative Commons Attribution 4.0 International License.

Read Full License

Version of Record: A version of this preprint was published at Geophysical Research Letters on June 8th, 2021. See the published version at https://doi.org/10.1029/2021GL093440. 


\section{Abstract}

The wintertime Arctic stratospheric polar vortex is characterized by a circumpolar westerly jet, confining the coldest temperatures over the Arctic. The future stratosphere is globally dominated by a strong radiative cooling due to the increase in greenhouse gases, enhancing the Arctic cooling. However, we find that over North America, the Arctic stratospheric cooling is suppressed or rather warming occurs, whereas over Eurasia stratospheric cooling is most pronounced, leading to an asymmetric polar vortex, based on 21 st century climate model simulations. There are many causes that drive polar vortex variability, such as Arctic sea ice loss, and midlatitude and tropical Pacific warming, which make future projections highly uncertain. Our model simulations demonstrate that tropical warming induces the asymmetric polar vortex. The eastern equatorial Pacific warming causes eastward-shifted teleconnection, which strengthens the polar vortex over Eurasia and weakens over North America by enhancing the vertical wave propagation into the stratosphere. The asymmetric polar vortex is projected to markedly develop in the 2030s, and so could also affect winter surface climate over mid- to high-latitudes of Eurasia in the near future.

\section{Introduction}

The larger topographic and land-sea contrasts in the Northern Hemisphere $(\mathrm{NH})$ produce stronger upward propagating planetary waves into the stratosphere than in the Southern Hemisphere (SH), causing the Arctic stratospheric polar vortex (hereafter polar vortex) more disturbed ${ }^{1}$. Recent weakening of the polar vortex ${ }^{2-4}$ is suggested to be associated with Arctic sea ice loss as a cause of recent Eurasian cooling ${ }^{5,6}$, although the underlying mechanisms is yet inconclusive ${ }^{7}$. In contrast, one recent study suggested that the polar vortex has strengthened since the 2000s associated with the North Pacific warming ${ }^{8}$, which has opposing influences with Arctic sea ice loss ${ }^{5,6,9,10}$. In particular, sea surface temperature (SST) is regarded as a major driver of polar vortex variability. El Niño Southern Oscillation (ENSO) affects the strength and variability of the polar vortex; El Niño events lead to a warming and weakening of the polar vortex ${ }^{11-14}$.

Considering the characteristics of the polar vortex with a centre over the pole (i.e., circumpolar westerly jet), many previous studies are based on the zonal mean fields. However, the polar vortex in February has slightly shifted away from North America towards Eurasia over the past three decades ${ }^{2,15}$, contributing to slow down the stratospheric ozone recovery over the Eurasian continent ${ }^{16}$. This is suggestive of an importance of the polar vortex shift or its horizontal distribution in the wavier $\mathrm{NH}$ than the $\mathrm{SH}$. Under increased greenhouse gas emissions a globally averaged stratospheric cooling is expected ${ }^{17,18}$, whereas this is suggested to be offset over the Arctic by a strengthened Brewer-Dobson circulation ${ }^{14,18,19}$, which make future projection on the polar vortex highly uncertain ${ }^{7,18,20}$. Our study shows that the polar vortex continues to shift towards Eurasia due to tropical Pacific warming, having an asymmetric structure between North America and Eurasia. 


\section{Main Text}

\section{Future asymmetry of the Arctic stratospheric polar vortex}

In the late 21 st century, tropospheric warming and stratospheric cooling are expected in both hemispheres (Fig. 1a). However, two major differences are found in both hemispheres: the middle stratospheric cooling above $50 \mathrm{hPa}$ is much weaker in the $\mathrm{NH}$ than in the $\mathrm{SH}$, and the lowermost stratospheric cooling at $150-200 \mathrm{hPa}$ is centred on the pole in the $\mathrm{SH}$, whereas in the $\mathrm{NH}$ near $60-70^{\circ} \mathrm{N}$. The former difference is most pronounced in boreal winter and suggests the competing effects of radiative cooling ${ }^{17,18}$ and dynamical Arctic warming due to a strengthened Brewer-Dobson circulation ${ }^{14,18,19}$. While the middle stratospheric cooling over the Arctic is the strongest in summer, the lowermost stratospheric cooling only occurs in autumn and winter (Fig. 1b), which produce the contrasting temperature responses between the lowermost and middle stratosphere.

Interestingly, in the lowermost (150 hPa) and middle ( $30 \mathrm{hPa})$ stratosphere, the Arctic cooling is the strongest over eastern Eurasia, whereas there is little model consensus on the cooling over North America (Fig. 1c, d). The future changed temperature difference between Eurasia and North America reaches approximately $5^{\circ} \mathrm{C}$ at $30 \mathrm{hPa}$, which is responsible for weaker Arctic stratospheric cooling in winter. In the lowermost stratosphere, the Pacific-North American-like (PNA) teleconnection pattern appears to be dominant (Fig. 1e). In the middle stratosphere, however, the polar vortex strengthens over Eurasia and weakens over North America, with the eastward shift compared with the climatological wave (Fig. 1f), indicating the shift of the polar vortex towards Eurasia ${ }^{2,15}$ or the enhancement of asymmetry between North America and Eurasia. These changes are also confirmed by a Student's $t$-test at the $99 \%$ confidence level (Supplementary Fig. 1). The wavenumber 1-like response to climate change has been suggested by some models ${ }^{21,22}$, but its cause remains unclear.

\section{Simulated polar vortex response to sea surface warming}

To explore what induces the asymmetric polar vortex response, we make use of existing simulations ${ }^{23}$ with an atmospheric general circulation model (AGCM). Although there are many causes that drive polar vortex variability $5,6,8-14$, our simulations enable to quantify the atmospheric response derived from (1) global SST warming and sea ice loss (GLSST), (2) Arctic sea-ice loss (AICE), (3) midlatitude SST warming (MLSST), and (4) tropical SST warming (LLSST), respectively (see Methods and Supplementary Fig. 2).

First, we discuss the vertical section of the zonal-mean temperature responses (Supplementary Fig. 3). The simulated GLSST response reproduces well the projected temperature response (Fig. 1a), except for the middle stratosphere. The difference between the simulated GLSST and projected model responses is produced by the direct radiative component and ocean-atmosphere coupling ${ }^{23}$. The polar vortex is weakened by AICE and strengthened by MLSST, which have opposing influences, consistent with previous studies $5,6,8-10$. The AICE- and MLSST-changed polar vortexes are centred near the pole in the 
middle stratosphere (Supplementary Fig. 4). The LLSST response captures well the simulated lowermost stratospheric cooling with a peak over $60^{\circ}-70^{\circ} \mathrm{N}$ in GLSST, accounting for the projected response. In the GLSST response the lowermost stratospheric cooling from autumn further into spring overestimates the projected response (Fig. 1b), due to AICE and MLSST, whereas the LLSST response reproduces well the seasonal evolution. In late winter, however, strong stratospheric warming descends from the middle to the lower stratosphere and is also slightly visible in GLSST, weakening the polar vortex.

Also in the horizontal distributions, the GLSST and LLSST responses capture well the projected lowermost stratospheric cooling with a peak over eastern Eurasia (Fig. 2a, b compared with Fig. 1c). Surprisingly, in the middle stratosphere, the GLSST and LLSST responses simulate Eurasian cooling and the warming over the North Pacific and North America (Fig. 2c, d). These results demonstrate that tropical SST warming induces the projected asymmetric temperature response (Fig. 1d), independent of the direct radiative cooling effect, Arctic sea ice loss, and midlatitude SST warming (Supplementary Fig. 4). The Eurasian cooling in the lowermost stratosphere is accompanied with a deepened Aleutian low (Fig. 2f) through the PNA pattern (Fig. 2j), corresponding with the projected circulation response (Fig. 1e). In the middle stratosphere, geopotential height responses show significant decreases over Eurasia along the Arctic coast and increases over North America (Fig. 2g, h). The wavenumber 1 -like responses reproduce well the projected response with the eastward shift compared to the climatological wave (Fig. 2k, I), leading to the asymmetric polar vortex. These features in GLSST and LLSST correspond well with ENSO impacts on the warming and weakening of the polar vortex; the deepened Aleutian low associated with the positive PNA pattern enhances vertical wave propagation into the stratosphere, which weakens the polar vortex ${ }^{11-14}$.

\section{Role of the eastern equatorial Pacific warming}

Returning to coupled model simulations, in the late 20th century, there are little significant SST correlations with the stratospheric temperatures over North America and Eurasia among the individual models in tropical oceans (Supplementary Fig. 5). In the late 21 st century, however, SST correlation with the North American temperature among the individual models positively increases in whole tropical oceans, and the Eurasian temperature negatively correlates with the western and eastern equatorial Pacific SST (Supplementary Fig. 5). These results support our AGCM simulations that tropical ocean warming induces the asymmetric polar vortex. In particular, the eastern equatorial Pacific, which plays the leading role in ENSO-induced PNA pattern, is expected to most significantly warm in the tropical Pacific ${ }^{24}$.

Figure 3a shows longitude-vertical section of regressed anomalies of temperature averaged $60^{\circ}-70^{\circ} \mathrm{N}$ onto the Niño-3 SST, as a representative of the eastern equatorial Pacific ${ }^{14}$. Eurasian cooling and North American warming are evident, indicating that warmer models in the eastern equatorial Pacific enhance the contrasting temperature response, which is consistent with the projected stratospheric temperature response (Fig. 3b). Remarkably, despite the strong radiative cooling, more than $80 \%$ of the individual 
models simulate stratospheric warming over North America approximately $1^{\circ} \mathrm{C}$ at $70 \mathrm{hPa}$ (Fig. 3b), which is consistent across the models (Supplementary Fig. 1). The contrasting temperature response to the Niño-3 SST warming is associated with the asymmetric polar vortex (Fig. 3c). The negative geopotential height anomalies display a westward tilt with altitude roughly from the date line between Eurasia and North America, indicative of vertical wave propagation ${ }^{25}$. This result implies that the planetary wave response to the Niño-3 SST warming interferes constructively with the climatological wave and enhances vertical wave propagation into the middle stratosphere, similar mechanism to recent shift of the polar vortex towards Eurasia ${ }^{15}$.

To validate the asymmetric polar vortex response to the eastern equatorial Pacific warming, we diagnose anomalous planetary waves using a linear baroclinic model (LBM) (see Methods). When an idealized heating is centred over the equator at $100^{\circ} \mathrm{W}$ under the present climatology, the LBM response also shows a westward tilt with altitude from the date line, enhances vertical wave propagation into the stratosphere, and shifts the polar vortex towards the Eurasian continent, leading to the asymmetric polar vortex with larger amplitude over North America (Fig. 3d). The eastward shifted and deepened Aleutian low through the PNA pattern plays a role in strengthening the planetary wave (Supplementary Fig. 6). Changes in the location or strength of the tropical thermal forcing can considerably affect wave propagation into the stratosphere ${ }^{11,14}$. When the idealized heating is centred at $120^{\circ} \mathrm{W}$, the LBM response still shows the asymmetric polar vortex, but at $140^{\circ} \mathrm{W}$ in the central Pacific, only weakens the polar vortex, and at $160^{\circ} \mathrm{E}$ in the western Pacific, has little influence on the polar vortex (Supplementary Fig. 6). Consequently, while the deepening of the Aleutian low weakens the polar vortex ${ }^{12-14}$, the eastward shift of the Aleutian low leads to the asymmetry by shifting the polar vortex to Eurasia. The eastward-shifted polar vortex response compared with the climatological wave (Figs. $1 f, 2 k$, l, and $3 c$ ) is consistent with the eastward shift of the Aleutian low.

In observations, it is difficult to discern the polar vortex responses to the central and eastern Pacific ENSO ${ }^{14,26}$. In the future, however, the eastward-shifted PNA pattern with the deepened Aleutian low is expected as a robust change $24,27,28$. The eastern equatorial Pacific warms faster than the surrounding regions ${ }^{24}$, exceeding the SST threshold for tropical convection ${ }^{27,29}$, which in turn induces the eastwardshifted PNA pattern and leads to the asymmetric polar vortex. Indeed, both coupled models and our AGCM simulations indicate equatorial wave response over the eastern tropical Pacific (Supplementary Fig. 7), as a result of increased precipitation in a comparable magnitude with the central equatorial Pacific (Supplementary Fig. 8).

\section{Possible impact on surface climate in the near future}

The observed asymmetric polar vortex begins to develop in the late 20th century ${ }^{2,15}$. The multi-model mean appears to capture recent weakening and shift of the polar vortex, and then the weakening becomes moderate by the 2030s (Fig. 4b), possibly due to the opposing effects of Arctic sea ice 
loss $5,6,9,10$ and midlatitude SST warming ${ }^{8}$ (Supplementary Fig. 4), although unforced internal variability might be sufficiently strong ${ }^{2,4,7}$. From the 2030s, however, the polar cap height rapidly increases over North America and decreases over Eurasia, asymmetrically enhancing the polar vortex. While Eurasian cooling increasingly becomes strong, North American cooling is suppressed and maintained close to the present temperature by 2100 (Fig. 4a). This rapid change in the 2030s suggests that tropical Pacific warming takes the place of Arctic sea ice loss and midlatitude SST warming as the dominating forcing of the polar vortex.

The stratospheric variations can have a strong impact on surface weather and climate through the stratosphere-troposphere coupling ${ }^{5,6,13,15,30}$. In the late 21 st century, subseasonal surface temperature variability (i.e., cold extremes) is projected to significantly decrease over the mid- to high-latitude $\mathrm{NH}$ due to Arctic amplification ${ }^{31}$. However, the cold extremes are likely to increase during a few decades from the 2030s (see Fig. 4 of ref. 31). Despite recent debate on the impact of Arctic sea ice loss ${ }^{7}$, in a few decades, the asymmetric polar vortex could act to increase the cold extreme events, such as recent cold-airoutbreak over Eurasia ${ }^{3}$. Indeed, composite analysis based on AGCM simulations (see Methods) shows that surface cooling (warming) is enhanced over Eurasia associated with a polar vortex shift towards Eurasia (no shift) (Supplementary Fig. 9), basically consistent with the impact of recent shift towards Eurasia on surface temperature ${ }^{15}$. Our results here provide a new insight into Arctic climate changes and important implications for the near future projection on surface climate. Contrary to highly uncertain future projections on the polar vortex $7,18,20$, the asymmetry is a robust change to be expected in the future.

\section{Methods}

Data and analyses. We used Coupled Model Intercomparison Program phase 5 (CMIP5) models ${ }^{32}$ (Supplementary Table 1). Atmospheric data were horizontally interpolated onto a $2.5^{\circ} \times 2.5^{\circ}$ grid and SST data were interpolated onto a $1^{\circ} \times 1^{\circ}$ grid. For the historical and Representative Concentration Pathway (RCP) 8.5 scenarios the response to anthropogenic forcing is defined as the difference between the 2070-2099 period from the RCP8.5 run and the 1970-1999 period from the historical run. All data used in this study were averaged over the 30 CMIP5 models, except that geopotential height is based on 29 models (unavailable HadGEM2-CC data). This study focuses on boreal winter (December-February). All regression and correlation analyses are conducted after linear detrending. The significance test used in this study is a standard two-tailed $t$-test.

AGCM simulations. We made use of the simulations conducted in our earlier study that focuses on tropospheric midlatitude jet ${ }^{23}$. All experiments use the Dennou-Club Planetary Atmospheric Model (DCPAM5) ${ }^{33}$ with 26 vertical layers extending to about $6.5 \mathrm{hPa}$ and a spectral resolution of T85, roughly equivalent to $1.4^{\circ} \times 1.4^{\circ}$. Further description of the model is provided in ref. 23 . 
As stratospheric variability is easily dependent on a model's lid height, we confirmed the reproducibility of the polar vortex (see Supplementary Fig. 10), although it is suggested that there is no clear link between a model's lid height and the response in inter-model differences ${ }^{18,20}$. The climatological zonal-mean jet is stronger than that in JRA55 reanalysis ${ }^{34}$, but its distribution is well reproduced. Despite the fact that many low-top models have much little stratospheric variability compared with reanalysis data ${ }^{35}$, our ensemble-member jet variability has a comparable magnitude with JRA55 reanalysis (approximately $8 \mathrm{~m}$ $\left.\mathrm{s}^{-1}\right)$. The horizontal distribution and variability of the polar vortex are also well captured in this model. These results confirm that our low-top model is suitable for understanding changes in the polar vortex.

Four experiments were performed (Supplementary Table 2). In HIST experiment, the model is forced globally with historical SST and sea ice distribution, while GLSST experiment is forced globally with RCP8.5 SST and sea ice distribution. AICE experiment is the same as HIST, except for RCP8.5 Arctic sea ice distribution. The GLSST and AICE responses are defined as the difference with HIST experiment. To obtain the atmospheric response due to mid- and low latitudes SST warming, we performed MLSST + AICE experiment, which is forced with RCP8.5 mid-latitude SST (north of $35^{\circ} \mathrm{N}: 15-35^{\circ} \mathrm{N}$ with linear tapering zones, so that RCP8.5 mid-latitude SST does not exceed the historical lower latitude SST) and Arctic sea ice distribution, but with historical conditions elsewhere. The mid-latitude SST warming (MLSST) response is estimated by subtracting AICE from MLSST + AICE experiment (see Supplementary Fig. 2). Similarly, the difference between GLSST and MLSST + AICE experiments provides the atmospheric response due to the low latitude (including the Southern Hemisphere) SST warming (LLSST response). The tropospheric thermodynamic responses in these experiments reflect global warming, Arctic sea ice loss, and mid-latitude and tropical SST warming (Fig. 2a-d). SST and sea-ice boundary data are obtained by averaging over the 30 CMIP5 models (i.e., climatology for the periods 1970-1999 and 2070-2099). The experiments were integrated for 30-year after 1-year spinup. In all of the experiments, radiative forcing is fixed at the 2000 level, following previous studies ${ }^{9,10}$.

For a composite analysis, we have detected latitude of minimum geopotential height at $50 \mathrm{hPa}$ from individual monthly data in HIST experiment. Years with the minimum geopotential height equatorward of $80^{\circ} \mathrm{N}$ and poleward of $83^{\circ} \mathrm{N}$ are defined as with and without a polar vortex shift, respectively. We have selected 24 cases with a polar vortex shift towards Eurasia and without a shift (Supplementary Fig. 11).

\section{LBM experiments.}

Atmospheric response to a prescribed diabatic heating was calculated by a linear baroclinic model $(\text { LBM })^{36}$ with a given climatological basic state and a thermal forcing. A LBM is an important diagnostic tool and widely used to simulate either anomalous or climatological stationary waves. A detailed description of the LBM is found in ref. 36. We here used a spectral resolution of T42 with 20 vertical layers. The vertical maximum of the heating $\left(1 \mathrm{~K} \mathrm{day}^{-1}\right)$ is placed at $500 \mathrm{hPa}$, and the half-width of the horizontal heating pattern is $20^{\circ}$ in longitude and $6^{\circ}$ in latitude. The basic state is based on the January 
climatology (averaged 1979-2010) from the National Centers for Environmental Prediction-National Center for Atmospheric Research (NCEP-NCAR) reanalysis ${ }^{37}$. Although the response to the diabatic heating grows with time, the response pattern does not change much after 10 days. The LBM responses in this study are based on 11-30 day mean.

\section{Data availability}

The CMIP5 datasets can be downloaded from the Earth System Grid Federation at https://pcmdi9.IInl.gov/projects/cmip5/. JRA55 reanalysis can be downloaded at https://jra.kishou.go.jp/JRA-55/index_en.html.

Code availability

The analysis codes and simulation data are available from the corresponding author upon reasonable request. DCPAM5 is available from http://www.gfd-dennou.org/library/dcpam/index.htm.en. All graphics were produced using GrADS version 2.1.0 (http://cola.gmu.edu/grads/).

\section{Declarations}

Acknowledgments. We acknowledge the WCRP's Working Group on Coupled Modelling and thank the climate modelling groups (Supplementary Table 1) for producing and making available their model output. Part of the AGCM simulations was conducted by S. Ueki. K.Y. was supported by the Arctic Challenge for Sustainability (ArCS) program in Japan. T.H. was supported by the Environment Research and Technology Development Fund (2-1904) of Environmental Restoration and Conservation Agency, Japan.

Author contributions. S.M. conceived the research, analysed the data, and wrote the manuscript with feedback from K.Y.; K.Y. designed and performed the LBM experiments. All authors contributed to the interpretation of the results.

Competing interests. The authors declare no competing interests.

\section{References}

1. Waugh, D., Sobel, A. H., \& Polvani, L. M. What is the polar vortex and how does it influence weather? Am. Meteorol. Soc. 98, 37-44 (2017).

2. Seviour, W. J. M. Weakening and shift of the Arctic stratospheric polar vortex: Internal variability or forced response? Res. Lett. 44, 3365-3373 (2017).

3. Kretschmer, M. et al. More-persistent weak stratospheric polar vortex states linked to cold extremes. Am. Meteorol. Soc. 99, 49-60 (2018). 
4. Garfinkel, I., Son, S.-W., Song, K., Aquila, V., \& Oman, L. D. Stratospheric variability contributed to and sustained the recent hiatus in Eurasian winter warming, Geophys. Res. Lett. 44, 374- 382 (2017).

5. Kim, B. M. et al. Weakening of the stratospheric polar vortex by Arctic sea-ice loss. Commun. 5, 4646 (2014).

6. Nakamura, T. et al. The stratospheric pathway for Arctic impacts on midlatitude climate. Res. Lett. 43, 3494-3501 (2016).

7. Screen, J.A., Bracegirdle, T.J. \& Simmonds, I. Polar climate change as manifest in atmospheric circulation. Clim. Change Rep. 4, 383-395 (2018).

8. Hu, D., Guan, Z., Tian, W., \& Ren, R. Recent strengthening of the stratospheric Arctic vortex response to warming in the central North Pacific. Commun. 9, 1697 (2018).

9. Peings, Y. \& Magnusdottir, G. Response of the wintertime Northern Hemisphere atmospheric circulation to current and projected Arctic sea ice decline: A numerical study with CAM5. Clim. 27, 244-264 (2014).

10. Sun, L., Deser, C. \& Tomas, R. A. Mechanisms of stratospheric and tropospheric circulation response to projected Arctic sea ice loss. Clim. 28, 7824-7845 (2015).

11. Manzini, E., Giorgetta, M. A., Esch, M., Kornblueh, L. \& Roeckner, E. The Influence of Sea Surface Temperatures on the Northern Winter Stratosphere: Ensemble Simulations with the MAECHAM5 Model. Clim. 19, 3863-3881 (2006).

12. Garfinkel, C. I. \& Hartmann, D. L. Different ENSO teleconnections and their effects on the stratospheric polar vortex. Geophys. Res. 113, 1044-1044 (2008).

13. Ineson, S., \& Scaife, A. The role of the stratosphere in the European climate response to El Niño. Geosci. 2, 32-36 (2009).

14. Domeisen, D. I., Garfinkel, C. I., \& Butler, A. H. The teleconnection of El Niño Southern Oscillation to the stratosphere. Geophys. 57, 5- 47 (2019).

15. Zhang, J., Wenshou, T., Chipperfield, M. P., Xie, F., \& Huang, J. Persistent shift of the Arctic polar vortex towards the Eurasian continent in recent decades. Clim. Change 6, 1094-1099 (2016).

16. Zhang, J. et al. Stratospheric ozone loss over the Eurasian continent induced by the polar vortex shift. Commun. 9, 206 (2018).

17. Manabe, S. \& Wetherald, R. T. The Effects of Doubling the $\mathrm{CO} 2$ Concentration on the climate of a General Circulation Model. Atmos. Sci. 32, 3-15 (1975).

18. Manzini, E. et al., Northern winter climate change: Assessment of uncertainty in CMIP5 projections related to stratosphere-troposphere coupling. Geophys. Res. 119, 7979-7998 (2014).

19. Karpechko, A. Y. \& Manzini, E. Arctic Stratosphere Dynamical Response to Global Warming. Clim. 30, 7071-7086 (2017).

20. Simpson, I. R., Hitchcock, P., Seager, R., Wu, Y., \& Callaghan, P. The Downward Influence of Uncertainty in the Northern Hemisphere Stratospheric Polar Vortex Response to Climate Change. Clim. 31(16), 6371-6391 (2018). 
21. Wang, L. \& Kushner, P. J. Diagnosing the stratosphere-troposphere stationary wave response to climate change in a general circulation model, Geophys. Res., 116, D16113 (2011).

22. Mitchell, D. M. et al. The Effect of Climate Change on the Variability of the Northern Hemisphere Stratospheric Polar Vortex, Atmos Sci., 69, 2608-2618 (2012).

23. Matsumura, S., Ueki, S. \& Horinouchi, T. Contrasting responses of mid-latitude jets to the North Pacific and North Atlantic warming. Res. Lett. 46, 3973-3981 (2019).

24. Cai, W. et al. ENSO and greenhouse warming. Clim. Change 5, 849-859 (2015).

25. Charney, J. G. \& Drazin, P. G. Propagation of planetary scale disturbances from the lower into the upper atmosphere. Geophys. Res. 66, 83-109 (1961).

26. Rao, J., \& Ren, R. Asymmetry and nonlinearity of the influence of ENSO on the northern winter stratosphere: 1. Observations. Geophys. Res. 121, 9000-9016 (2016).

27. Zhou, Z., Xie, S.-P. Zheng, X. Liu, Q. \& Wang, H. Global Warming-Induced Changes in El Niño Teleconnections over the North Pacific and North America. Clim. 27, 9050-9064 (2014).

28. Gan, B. et al. On the Response of the Aleutian Low to Greenhouse Warming. Clim. 30, 3907-3925 (2017).

29. Johnson, N. C. \& Xie, S.-P. Changes in the sea surface temperature threshold for tropical convection. Nature Geosci. 3, 842-845 (2010).

30. Baldwin, M. P. \& Dunkerton, T. J. Stratospheric harbingers of anomalous weather regimes. Science 294, 581-584 (2001).

31. Screen, J. A. Arctic amplification decreases temperature variance in northern mid- to high-latitudes. Clim. Change 4, 577-582 (2014).

32. Taylor, K. E., Stouffer, R. J., \& Meehl, G. A. An overview of CMIP5 and the experiment design. Amer. Meteor. Soc. 93, 485-498 (2012).

33. Takahashi, Y. O. \& DCPAM Devlopment Group DCPAM: planetary atmosphere model, http://www.gfddennou.org/library/dcpam/index.htm.en.

34. Kobayashi, S. et al. The JRA-55 Reanalysis: General specifications and basic J. Meteor. Soc. Jpn. 93, 5-48 (2015).

35. Kim, J., Son, S., Gerber, E.P., \& Park, Defining Sudden Stratospheric Warming in Climate Models: Accounting for Biases in Model Climatologies. J. Clim. 30, 5529-5546 (2017).

36. Watanabe, M. \& Kimoto, M. Atmosphere-ocean thermal coupling in the North Atlantic: a positive feedback. J. Roy. Meteorol. Soc. 126, 3343-3369 (2000).

37. Kalnay, E. et al. The NCEP/NCAR 40-Year Reanalysis Project. Amer. Meteor. Soc. 77, 437-471 (1996).

\section{Figures}



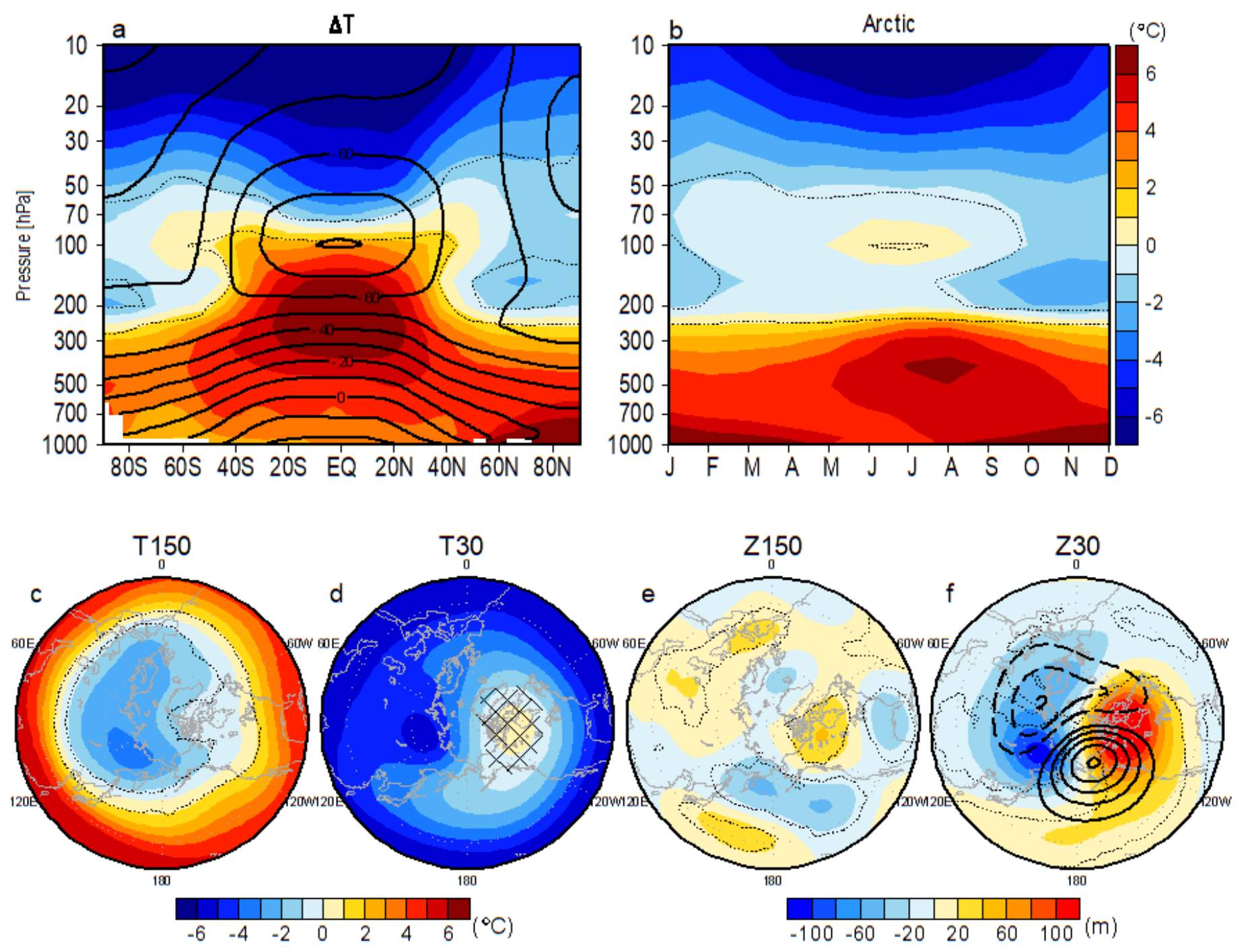

Figure 1

Future changes in temperature and polar vortex. (a) Vertical section of zonal-mean temperature difference between the means over 2070-2099 and 1970-1999 from CMIP5 models in boreal winter (December-February). Solid contours denote the historical temperature climatology (1970-1999). As in (a), but for (b) time-vertical section of the Arctic temperature difference (poleward of $60^{\circ} \mathrm{N}$ ) as a function of calendar month and (c) 150-hPa and (d) 30-hPa temperature differences. (e) and (f) As in (c) and (d), but for non-zonal component of geopotential height differences (shaded) and the historical climatology (contour interval is $100 \mathrm{~m}$, with the zero contour omitted; solid for positive and dashed for negative). Dotted contours and hatching indicate $\geq 80 \%$ and $<80 \%$ model agreement on the sign of the difference, respectively. 


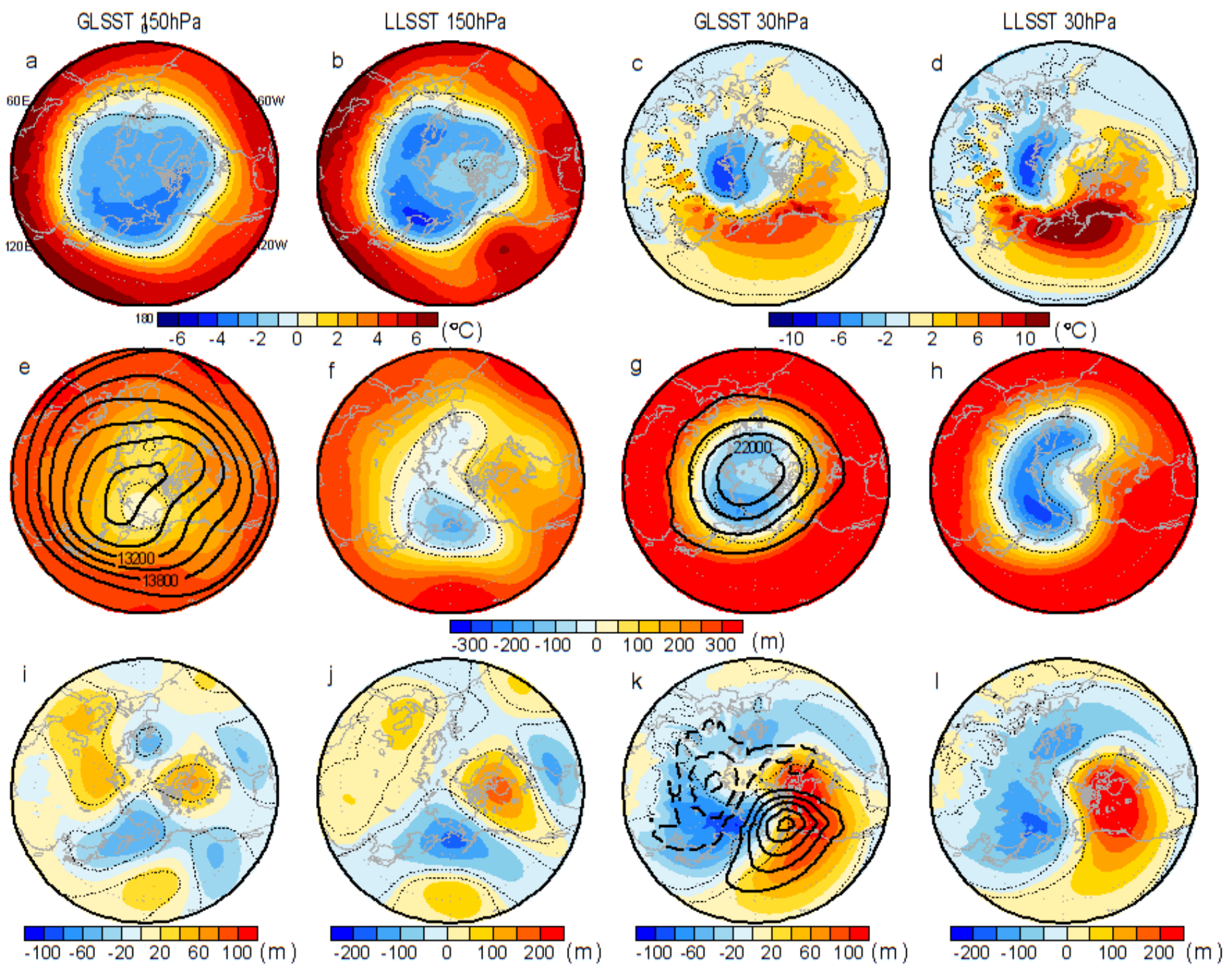

Figure 2

Simulated polar vortex responses to global and tropical warming. Response of wintertime temperature in (a) global SST warming and sea ice loss (GLSST) and (b) tropical SST warming (LLSST) at $150 \mathrm{hPa}$. (c) and (d) As in (a) and (b), but for $30 \mathrm{hPa}$. As in ( $a-d)$, but for (e-h) geopotential height and (i-l) non-zonal component of geopotential height. Dotted contours indicate statistical significance at the $99 \%$ level. Thick contours denote the climatology in HIST experiment (contour interval is $300 \mathrm{~m}$ in (e), $500 \mathrm{~m}$ in (g), and $100 \mathrm{~m}$ with the zero contour omitted in (k); solid for positive and dashed for negative). 

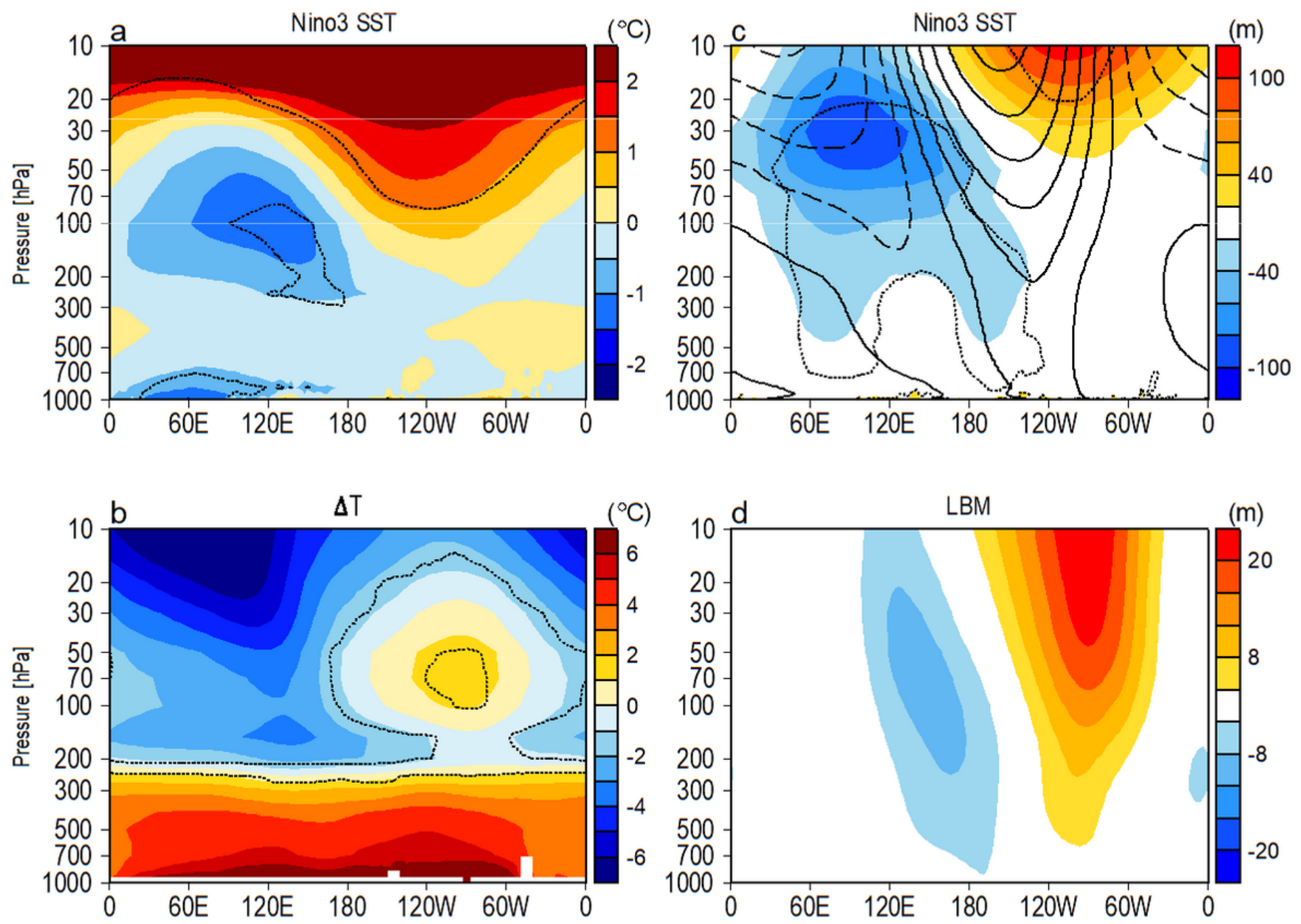

\section{Figure 3}

The asymmetric response to the eastern equatorial Pacific warming. Longitude-vertical section of regressed anomalies of (a) temperature and (c) geopotential height averaged between $60^{\circ}$ and $70^{\circ} \mathrm{N}$ onto standardized Niño-3 SST $\left(5^{\circ} \mathrm{S}-5^{\circ} \mathrm{N}, 90^{\circ}-150^{\circ} \mathrm{W}\right)$ among the individual CMIP5 models in $2070-2099$ climatology. (b) As in (a), but for temperature difference between the means over 2070-2099 and 19701999. (d) As in (c), but for LBM response to an idealized heating centred over the equator at $100^{\circ} \mathrm{W}$ with the present January basic state. Dotted contours indicate statistical significance over the $95 \%$ level in (a) and (c), and $\geq 80 \%$ model agreement on the sign of the difference in (b). Thick contours in (c) denote the climatological total waves (contour interval is $150 \mathrm{~m}$; solid for positive, dashed for negative, and thick solid for zero). 

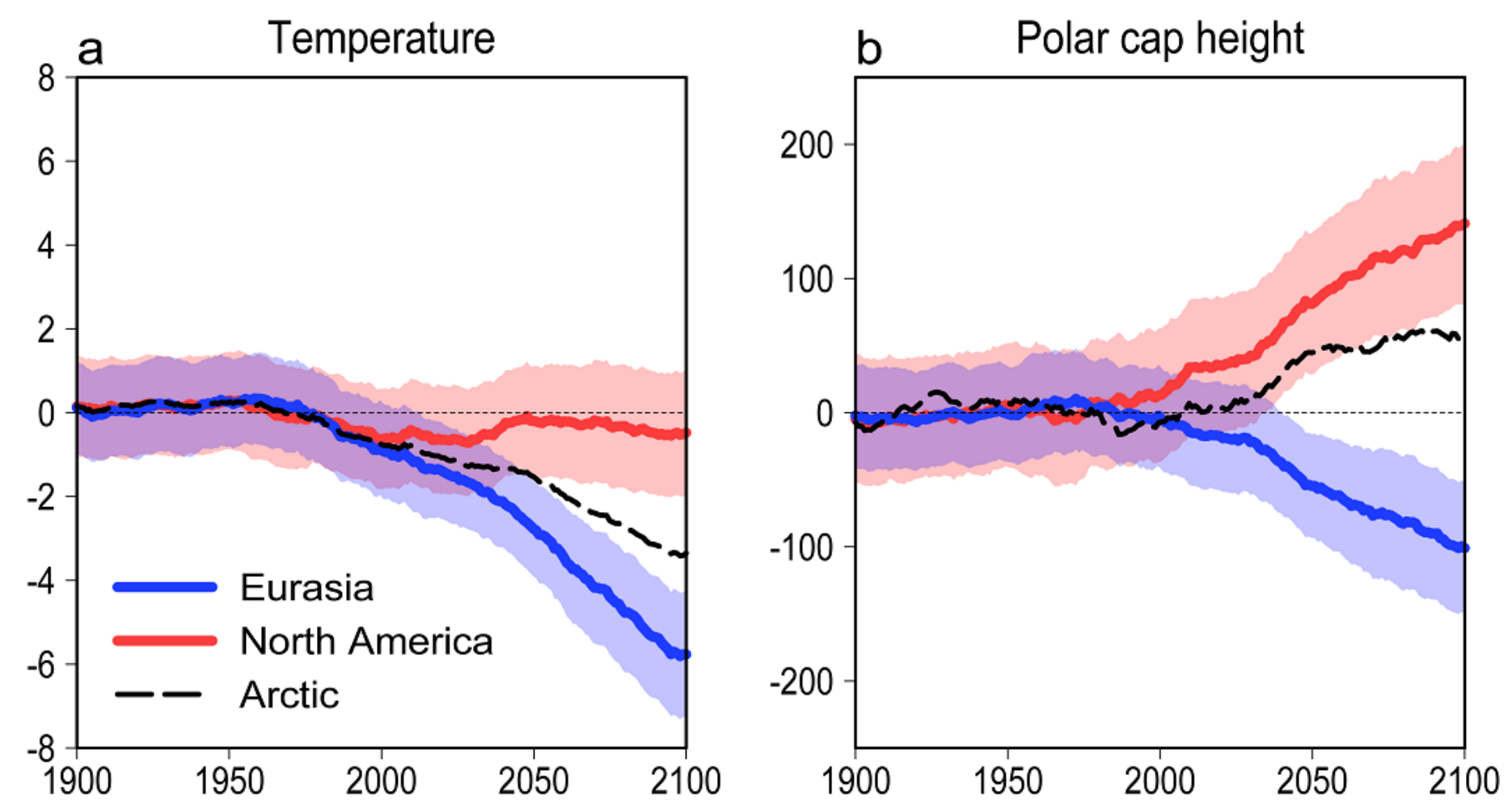

Figure 4

Asymmetrically changing polar vortex. Time series of 50-10 hPa mean (a) temperature $\left({ }^{\circ} \mathrm{C}\right)$ and $(\mathrm{b})$ polar cap height $(\mathrm{m})$ anomalies over Eurasia (blue line), North America (red line), and the Arctic (black dashed line) from 1900 to 2100 , relative to the 1901-2000 mean. All the lines and shadings indicate the multimodel mean and \pm 2 standard error (95\% confidence range) among the models, respectively, with 21-year running means. Temperature is averaged over Eurasia $\left(100^{\circ}-150^{\circ} \mathrm{E}, 60^{\circ}-70^{\circ} \mathrm{N}\right)$, North America $\left(60^{\circ}-\right.$ $110^{\circ} \mathrm{W}, 60^{\circ}-70^{\circ} \mathrm{N}$ ), and the Arctic (poleward of $60^{\circ} \mathrm{N}$ ). Polar cap height over Eurasia and North America is based on non-zonal component of geopotential height averaged over poleward of $60^{\circ} \mathrm{N}$.

\section{Supplementary Files}

This is a list of supplementary files associated with this preprint. Click to download.

- Suppl.pdf 